\title{
PULMONARY FUNCTION STUDIES IN NORMAL BOYS
}

\author{
BY
}

\author{
M. C. S. KENNEDY, D. C. THURSBY-PELHAM and P. D. OLDHAM \\ From the North Staffordshire Royal Infirmary, Stoke on Trent, and the Medical Research Council's Pneumoconiosis \\ Research Unit, Llandough
}

(RECEIVED FOR PUBLICATION DECEMBER 4, 1956)

That wheezy asthmatic children are unable to aerate their lungs as effectively as normal children has long been recognized, and it is generally believed that the severity of the 'asthma' is closely related to disturbance of the bellows function of the lungs. We have found subjective questioning and clinical examinations to be inadequate and of ten misleading for the assessment of asthmatic children. Consequently simple pulmonary function studies have been made as a routine on children attending an asthma clinic to provide a quantitative measure of disability, and to study more precisely the natural history of the various disease processes that give rise to asthma and difficulty in breathing. Such measurements are also useful in assessing quantitatively various forms of therapy, and help in differentiating reversible from irreversible lung changes.

Stewart (1922), Wilson and Edwards (1921), Moore and Gibson-Williams (1951) and others have shown that the pulmonary function of normal children varies with age and anthropometric build. However, the normal values of pulmonary function are dependent not only on the population studied but on the method of assessment and the apparatus used. At present it seems necessary for each group of workers to establish their own normal values (Wright, 1946). Therefore in this paper we report the results of pulmonary function studies and anthropometric measurements of 175 normal schoolboys between the ages of 8 and 14 years. We made this study in 1949 to provide the range of values that occur in normal schoolboys and to enable us to predict normal values for children of known age and stature.

\section{Selection of Normal Children}

The school from which the children were drawn was a state school in the Stoke-on-Trent area. The majority of the fathers were employed in the pottery and coal-mining industries. A nominal roll of all boys, listed according to age, was supplied by the school authorities, and from this list 175 children were chosen by random selection, in such a way as to give an unbiased sample of 25 children in each age group to cover each year of life between 8 and 14 inclusive. This random selection also provided two 'extras' for each age group should any child be found abnormal on clinical examination. Any child with clinical evidence of abnormalities of the respiratory system was excluded from the investigation.

\section{Methods}

Pulmonary Function Studies. The indices of ventilatory function that are listed below, together with their definitions, were carried out on each of the 175 normal children. All indices were measured in the sitting position with a nose clip. All values were corrected to $37^{\circ} \mathrm{C}$. and saturated with water vapour.

Vital Capacity (V.C.). This is the maximum volume of air that can be expelled after a full inspiration. In this report the V.C. is taken as the mean of four readings as recommended by Gilson and Hugh-Jones (1949) and expressed in millilitres.

Vital Spirogram (V.S.). This is the tracing of the vital capacity, or full expiration, followed by full inspiration (Kennedy, 1953a). The expiratory phase is termed the expiratory vital spirogram (E.V.S.) and the inspiratory phase the inspiratory vital spirogram (I.V.S.).

The Expiratory Flow Rate (E.F.R. $\left.{ }^{40}\right)$. This is half the expiratory flow rate during the first 0.75 second of the E.V.S. and is measured by means of a transparent protractor (Kennedy, 1953b). It is termed E.F.R. ${ }^{40}$, since an expiratory time interval of $0.75 \mathrm{sec}$. is equivalent to a theoretical breathing rate of 40 breaths per minute. The E.F.R. ${ }^{40}$ is taken as the mean of four readings and expressed in litres per minute.

The Inspiratory Flow Rate (I.F.R. ${ }^{40}$ ). This may be defined as above, but the inspiratory curve of the vital spirogram (I.V.S.) is measured instead of the E.V.S. 
Maximum Voluntary Ventilation (M.V.V.) (Maximum Breathing Capacity or M.B.C.). This index was first described by Hermannsen (1933) and is defined as the maximum volume of air that can be shifted in unit time by voluntary hyperventilation. In this investigation each boy was asked to breathe in and out of a spirometer as deeply and as quickly as possible and the volume of air shifted was recorded on a kymograph. The mean of three six-second runs was taken as the M.V.V. and expressed in litres per minute.

Two Spirometers. The measures were obtained using two spirometers. A spirometer similar to that described by Gilson and Hugh-Jones (1949) was used for the various pulmonary function studies of boys between the ages 11 and 14 inclusive (Spirometer A). The shell of a Kendrick B.M.R. apparatus was modified to provide a smaller spirometer (Spirometer B) for the measurements on the younger boys aged 8-10 inclusive.

The kymographs used with spirometers A and B had drum periphery speeds of $1.24 \mathrm{~cm}$./sec. and $1.0 \mathrm{~cm} . / \mathrm{sec}$. respectively.

Anthropometric Measurements. The following anthropometric measurements were made with the child in socks stripped to the waist: The weight in lb., the height, the stem height and the chest measurements at the level of the nipples were made to the nearest quarter inch.

\section{Results}

Fig. 1 shows a vital spirogram typical of that found in a normal child of $11 \frac{1}{2}$ years. It will be seen that the expiratory phase is linear and uniform except during the expulsion of the last small volume of air, whilst the inspiratory phase is linear throughout its whole length. From a glance at the spirogram it can be seen what fraction of the vital capacity is the most efficient for hyperventilation. In thi. typical example taken from a normal healthy boy, it is apparent that all parts of the vital capacity, except for the last part of expiration, can be inhaled and expelled with almost equal efficiency.

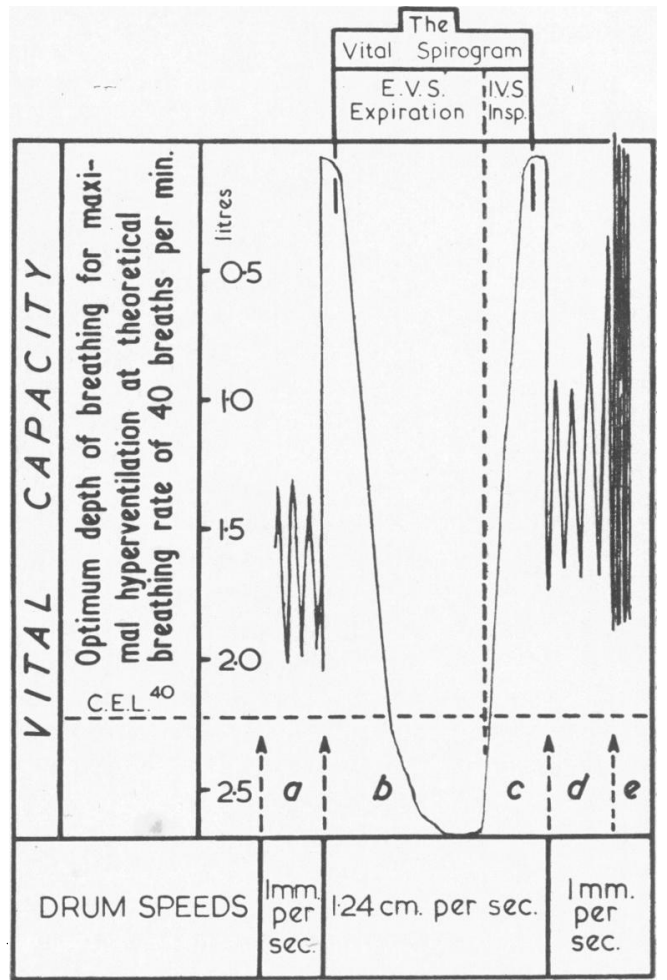

FIG. 1.-This continuous spirometric record of a normal boy aged $11 \frac{1}{2}$ shows:

(a) Quiet breathing at rest; (b) expiratory vital spirogram (E.V.S.); (c) inspiratory vital spirogram (I.V.S.); (d) quiet breathing $+\mathrm{CO}_{2}$; (e) M.V.V. tracing at 65 breaths per minute.

R.R.L. = Resting respiratory level.

C.E.L. $40=$ Critical expiratory level at theoretical breathing, rate of 40 breaths per minute.

TABLE 1

ANTHROPOMETRIC AND SPIROMETRIC MEASUREMENTS IN 175 NORMAL BOYS

\begin{tabular}{|c|c|c|c|c|c|c|c|c|c|c|c|}
\hline \multirow{2}{*}{$\begin{array}{l}\text { No. of Boys } \\
\text { in Each Group }\end{array}$} & \multirow{2}{*}{$\begin{array}{l}\text { Mean Age } \\
\text { (yr.) }\end{array}$} & \multirow{2}{*}{$\begin{array}{c}\text { Mean Wt. } \\
\text { (lb.) }\end{array}$} & \multirow{2}{*}{$\begin{array}{l}\text { Mean Ht. } \\
\quad \text { (in.) }\end{array}$} & \multirow{2}{*}{$\underset{\text { (in.) }}{\text { Mean Stem Ht. }}$} & \multicolumn{2}{|c|}{$\begin{array}{l}\text { Mean Chest Circum- } \\
\text { ference (in.) }\end{array}$} & \multirow{3}{*}{ 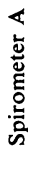 } & \multirow{2}{*}{$\begin{array}{l}\text { V.C. } \\
(\mathrm{ml} .)\end{array}$} & \multirow{2}{*}{$\begin{array}{l}\text { M.V.V. } \\
(1 . / \mathrm{min} .)\end{array}$} & \multirow{2}{*}{$\begin{array}{l}\text { E.F.R. }{ }^{40} \\
(1 . / \mathrm{min} .)\end{array}$} & \multirow{2}{*}{$\begin{array}{l}\text { I.F.R. }{ }^{40} \\
(1 . / \mathrm{min} .)\end{array}$} \\
\hline & & & & & Inspiration & Expiration & & & & & \\
\hline $\begin{array}{l}25 \\
25 \\
25\end{array}$ & $\begin{array}{l}8+5 \mathrm{mth} . \\
9+6 \mathrm{mth} . \\
10+5 \mathrm{mth} .\end{array}$ & $\begin{array}{l}58 \\
65 \\
67\end{array}$ & $\begin{array}{l}50 \\
52 \\
54\end{array}$ & $\begin{array}{l}28 \\
29 \\
30\end{array}$ & $\begin{array}{l}26 \\
27 \\
27\end{array}$ & $\begin{array}{l}24 \\
24 \\
24\end{array}$ & & $\begin{array}{l}1688 \\
1785 \\
1975\end{array}$ & $\begin{array}{l}55 \\
66 \\
71\end{array}$ & $\begin{array}{l}57 \\
58 \\
65\end{array}$ & $\begin{array}{l}42 \\
48 \\
54\end{array}$ \\
\hline $\begin{array}{l}25 \\
25 \\
25 \\
25\end{array}$ & $\begin{array}{c}11+7 \text { mth. } \\
\text { (3 mth.) } \\
12+4 \text { mth. } \\
\text { (3 mth.) } \\
13+6 \text { mth. } \\
\text { (3 mth.) } \\
14+5 \text { mth. } \\
\text { (3 mth.) }\end{array}$ & $\begin{array}{l}74 \\
(13) \\
77 \\
(9) \\
90 \\
(14) \\
104 \\
(12)\end{array}$ & $\begin{array}{l}55 \\
(2) \\
56 \\
(3) \\
59 \\
(4) \\
62 \\
(2)\end{array}$ & $\begin{array}{l}30 \\
(1) \\
31 \\
(1) \\
32 \\
(2) \\
34 \\
(2)\end{array}$ & $\begin{array}{l}28 \\
(2) \\
28 \\
(1) \\
30 \\
(2) \\
31 \\
(1)\end{array}$ & $\begin{array}{l}25 \\
(2) \\
26 \\
(1) \\
27 \\
(2) \\
28 \\
(1)\end{array}$ & 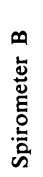 & $\begin{array}{l}2083 \\
(245) \\
2158 \\
(368) \\
2405 \\
(508) \\
2986 \\
(450)\end{array}$ & $\begin{array}{l}71 \\
(12) \\
76 \\
(14) \\
76 \\
(14) \\
99 \\
(16)\end{array}$ & $\begin{array}{l}71 \\
(10) \\
77 \\
(13) \\
83 \\
(14) \\
103 \\
(14)\end{array}$ & $\begin{array}{l}70 \\
(15) \\
73 \\
(15) \\
72 \\
(14) \\
100 \\
(19)\end{array}$ \\
\hline
\end{tabular}


Spirometric Measurements at Different Age Groups. The average values of the anthropometric and spirometric measurements of the 25 boys in each of the different age groups are given in Table 1.

The vital capacity values rise fairly uniformly by between $75 \mathrm{ml}$. and $247 \mathrm{ml}$. with each extra year of life up to 13 years of age. Between 13 and 14 the vital capacity increases by more than $500 \mathrm{ml}$. as shown graphically in Fig. 2 . The results suggest

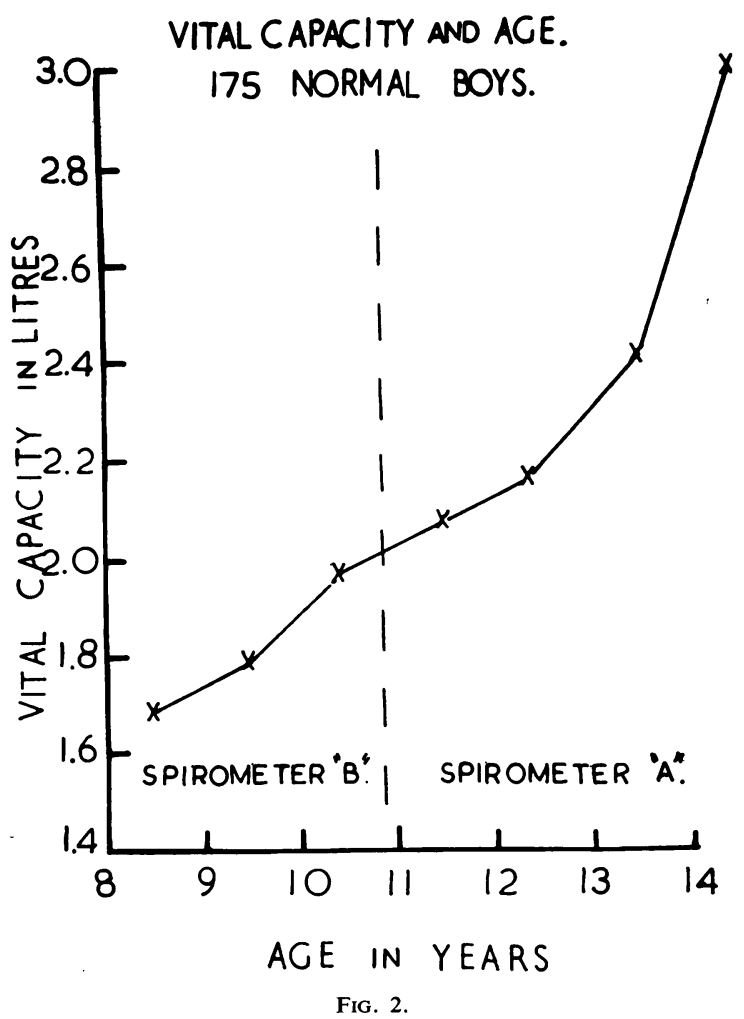

that the type of spirometer has had very little effect on the vital capacity readings.

The mean values of the M.V.V. and E.F.R. ${ }^{40}$ and I.F.R. ${ }^{40}$ for each age group are plotted in Fig. 3. Theoretically, one would expect the M.V.V. curve to lie between the E.F.R. ${ }^{40}$ and the I.F.R. ${ }^{40}$ curves. However, with spirometer B, the mean M.V.V. values of the 9- and the 10-year-olds are higher than the corresponding E.F.R. ${ }^{40}$ and I.F.R. ${ }^{40}$ values. This anomoly is almost certainly instrumental and may be explained by the fact that the oscillation of the water column was considerably greater in spirometer $B$ than in spirometer A during the performance of the M.V.V. test. This effect of a 'swinging' water column in enhancing M.V.V. values at different rates of breathing has been fully investigated by Bernstein, D' Silva and Mendel (1952).

The mean values of the M.V.V., E.F.R. ${ }^{40}$ and I.F.R. ${ }^{40}$ of the children measured with spirometer A closely approximate to one another and they all show the greatest yearly increase in the 14-year-olds. The mean E.F.R. ${ }^{40}$ increases remarkably uniformly in the age groups 9 to 13 inclusive, suggesting that

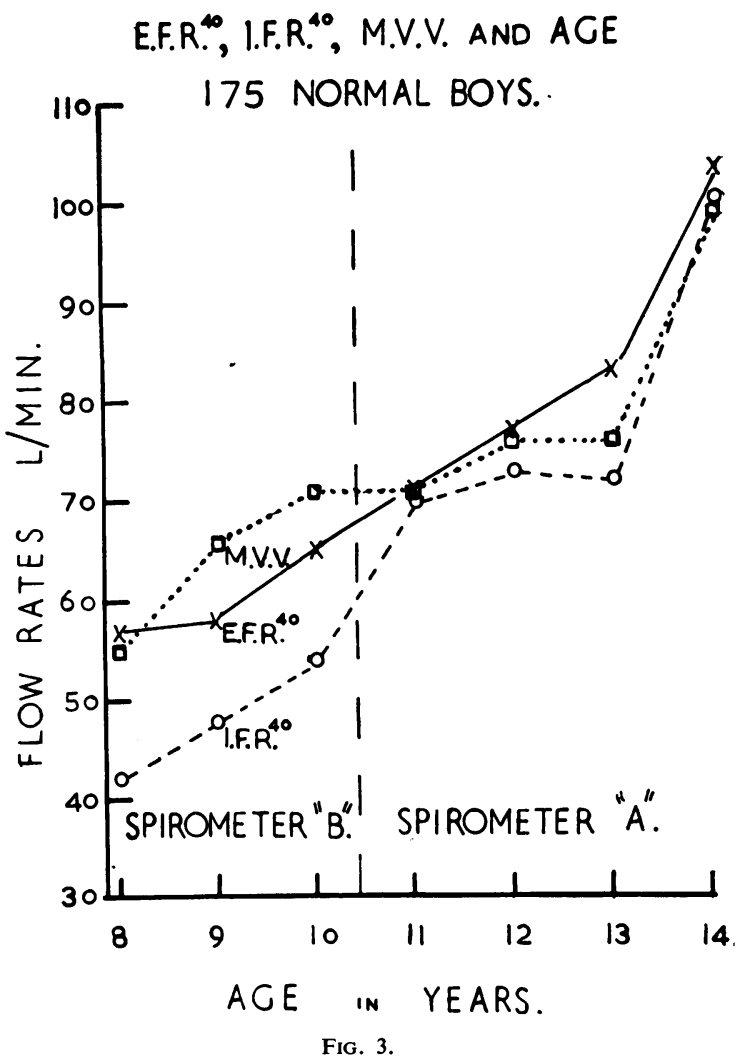

this index, unlike the M.V.V., is not unduly affected by the type of spirometer.

Interrelation of Spirometric and Anthropometric Measurements. The interrelation of the various indices is shown by the correlation coefficients which are listed in Table 2. These correlation coefficients relate to measurements made with spirometer $A$ on 100 boys, as in all our later studies we have employed only this spirometer which is suitable for the assessment of both adults and children.

Of the anthropometric measures stem height shows the best correlation with the spirometric measures, followed by standing height and weight, whilst age and the various chest measurements show less 
TABLE 2

CORRELATION COEFFICIENTS AT AGES 11 TO 14

\begin{tabular}{|c|c|c|c|c|c|c|c|c|c|c|c|}
\hline & Height & $\begin{array}{c}\text { Standing } \\
\text { Height }\end{array}$ & Weight & $\begin{array}{c}\text { P.A. } \\
\text { Inspiration }\end{array}$ & $\begin{array}{c}\text { P.A. } \\
\text { Expiration }\end{array}$ & $\begin{array}{l}\text { Circum- } \\
\text { ference } \\
\text { Inspiration }\end{array}$ & $\begin{array}{c}\text { Circum- } \\
\text { ference } \\
\text { Expiration }\end{array}$ & Age & E.F.R. & I.F.R. & V.C. \\
\hline Standing height & $0 \cdot 720$ & - & - & 一 & - & - & - & - & 一 & - & - \\
\hline Weight & 0.848 & 0.782 & - & - & - & - & - & - & - & - & - \\
\hline P.A. inspiration & 0.575 & 0.673 & 0.695 & - & - & - & - & - & 一 & - & - \\
\hline P.A. expiration & 0.511 & 0.474 & 0.673 & 0.897 & - & - & - & - & - & - & 一 \\
\hline inspiration & $0 \cdot 222$ & $0 \cdot 183$ & 0.290 & 0.232 & 0.233 & - & 一 & - & - & 一 & - \\
\hline $\begin{array}{c}\text { Circumference } \\
\text { expiration }\end{array}$ & 0.672 & 0.492 & 0.855 & 0.661 & 0.655 & $0 \cdot 285$ & - & - & - & - & - \\
\hline Age $\ldots$ & 0.676 & 0.692 & 0.676 & 0.430 & 0.447 & 0.193 & 0.584 & - & - & - & - \\
\hline E.F.R. & 0.772 & $0 \cdot 768$ & $0 \cdot 702$ & 0.594 & 0.524 & $0 \cdot 210$ & 0.518 & 0.620 & - & - & - \\
\hline I.F.R. & 0.507 & 0.588 & 0.468 & 0.428 & 0.352 & $0 \cdot 143$ & $0 \cdot 326$ & 0.418 & 0.786 & - & - \\
\hline $\begin{array}{lll}\text { V.C. } & \cdots\end{array}$ & $\begin{array}{l}0.812 \\
0.627\end{array}$ & $\begin{array}{l}0.847 \\
0.711\end{array}$ & $\begin{array}{l}0.801 \\
0.639\end{array}$ & $\begin{array}{l}0.637 \\
0.497\end{array}$ & $\begin{array}{l}0.578 \\
0.449\end{array}$ & 0.243 & 0.638 & 0.602 & 0.893 & $\begin{array}{l}0.625 \\
0.936\end{array}$ & $\overline{0.705}$ \\
\hline M.B.C. $\quad \cdots$ & & & & & & $0 \cdot 184$ & $0 \cdot 485$ & & & 0.950 & 0.105 \\
\hline
\end{tabular}

correlation. Of the spirometric measures the V.C. shows the best correlation with stem height, standing height and weight followed by E.F.R. ${ }^{40}$ and M.V.V. and with the I.F.R. ${ }^{40}$ showing the lowest correlation. Within the four spirometric measures, the vital capacity correlates best with the E.F.R. ${ }^{40}(r=0.893)$ whilst the M.V.V. correlates best with the I.F.R. ${ }^{40}$ $(r=0.936)$. For reasons which are discussed later we have employed the E.F.R. ${ }^{40}$ as our measure of the bellows function of the lungs: we will now consider how we may predict normal values for boys of known age and build.

Estimation of Expected Normal E.F.R. ${ }^{40}$ of a Boy. The three anthropometric measurements that correlate best with the E.F.R. ${ }^{40}$ are standing height $(r=0.772)$, stem height $(r=0.786)$ and weight $(r=0 \cdot 702)$, whilst some of the chest measurements show a smaller but significant correlation. For the assessment of results in abnormal children it is necessary to be able to predict normal valuesweight and chest measurements are usually more altered by disease processes than height-and we have therefore rejected the former measures for prediction purposes. We consider height and age to be the most relevant indices for calculating the expected normal E.F.R. ${ }^{40}$, and employ the following regression equation.

$$
\begin{array}{r}
\text { E.F.R. } .^{40}=3 \cdot 23 \times X_{1}+2 \cdot 41 \times X_{2}-135 \\
\text { where } X_{1}=\text { height in inches } \\
X_{2}=\text { age in years }
\end{array}
$$

For convenience in clinical work this regression equation has been translated into a nomogram (Fig. 4). If on the nomogram, the age and height of a subject be joined by a ruler, the predicted E.F.R. ${ }^{40}$ is given by the point of intersection with the E.F.R. ${ }^{40}$ scale.

Regression Equations for Prediction of V.C., M.V.V. and I.F.R. ${ }^{40}$ in Boys Aged 11-14 Years. If for the reasons given previously one excludes weight and chest measurements for the prediction of normal values of the V.C., M.V.V., and I.F.R. ${ }^{40}$, the best prediction formulae for the various indices on the basis of standing height are given below. The prediction of the indices listed below is not materially improved by allowing for age as well.

V.C. $=115 \cdot 93 \mathrm{x}_{1}-4348 \mathrm{ml}$. (S.D. $290 \mathrm{ml}$. ).

M.V.V. $=2 \cdot 98 \mathrm{x}_{1}-93 \cdot 4 \mathrm{l} . / \mathrm{min}$. (S.D. $\left.13 \cdot 2 \mathrm{l} . / \mathrm{min}.\right)$.

I.F.R. ${ }^{40}=3 \cdot 06 \mathrm{x}_{1}-97 \cdot 41 . / \mathrm{min}$. (S.D. $\left.15 \cdot 71 . / \mathrm{min}\right)$. . where $\mathrm{x}_{1}=$ standing height in inches.
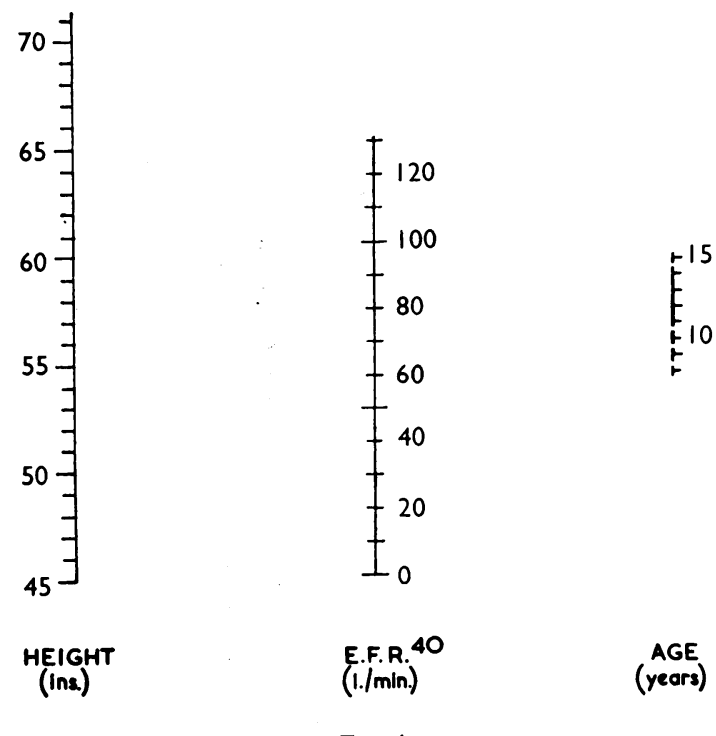

FIG. 4.

\section{Discussion}

The results of the various spirometric measures on the 175 normal school children presented in this paper were all obtained in a school room temporarily 
set aside for the purpose. The four spirometric measures (V.C., M.V.V., E.F.R. ${ }^{40}$ and I.F.R. ${ }^{40}$ ) of each individual boy that have been included in with those studied by Stewart (1922), Needham, Rogan and McDonald (1954) and Higgins, Oldham, the analysis are the mean of four consecutive values. We think it important to stress these conditions under which the observations were made, and also the method of analysis, because we believe these factors may be responsible for our predicted and recorded values being slightly lower than those reported by some other authors.

\section{Absolute Values Compared with Those of Previous Workers. The different absolute values of the various spirometric measures reported here and by previous workers can largely} be explained on the basis of three variables, namely, the physical characteristics of the children studied, the method and the procedure employed in obtaining the results.

Fig. 5 shows the standing height and age of the boys studied by us and of boys studied by previous workers with comparable data, whilst Fig. 6 gives the vital capacity plotted against age. If Figs. 5 and 6 be compared, it will be seen that the highest vital capacities at the different ages were reported by those workers (Robinson, 1938; Moore and Gibson-Williams, 1951) who studied taller boys than the other workers. The heights of the boys of different ages reported by us appear comparable

Merrick and Dunsdon (1956). Our V.C. values

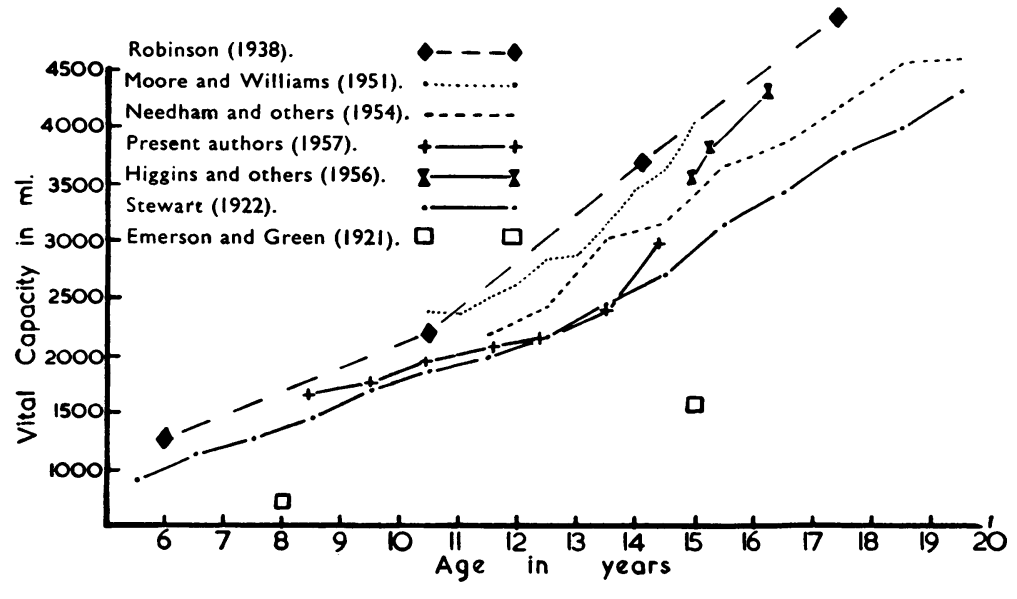

FIG. 6.

agree well with those of Stewart and also of Everley Jones (1955), who studied a group of Midland school children similar to our sample. The values obtained by Needham et al. for boys aged 11 to 14 inclusive are slightly higher than our values, possibly because they took the highest of four attempts as the V.C., whereas we took the mean of four attempts as recommended by Gilson and Hugh-Jones (1949). The low values reported by Emerson and Green (1921) cannot be explained on the basis of height, and it is possible that the big differences between these and other authors may be due to the apparatus used. Higgins et al. used a low-resistance spirometer almost identical to our adult spirometer and, allowing for the height differences,

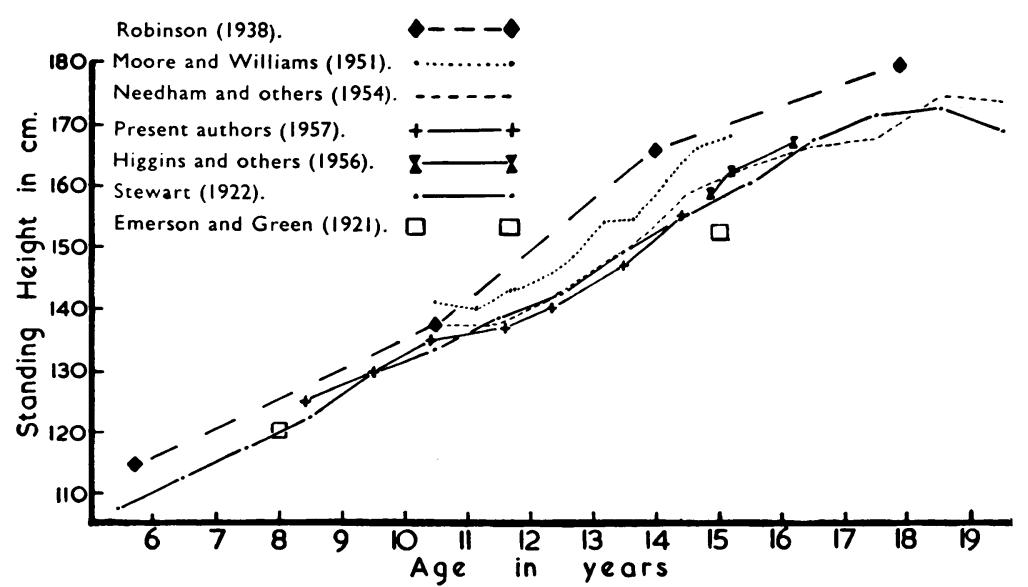

Fig. 5. the V.C. value of their 14-yearolds seem compatible with our values. Most of the data in Fig. 6 show that the vital capacity, like the height, increases more during the years of puberty.

Morse, Schlutz and Cassels (1952), studied normal boys aged 11-17 years, and found that the vital capacity occupies roughly $80 \%$ of the total lung volume; this finding also holds true for normal young adults (Kaltreider, Fray and Hyde, 1938; Robinson, 1938). Thus, if one finds the vital capacity of an adolescent or a young adult to be as good or better 
than the predicted normal value, then it would be reasonable to expect the other sub-divisions of the total lung volume to be within normal limits also.

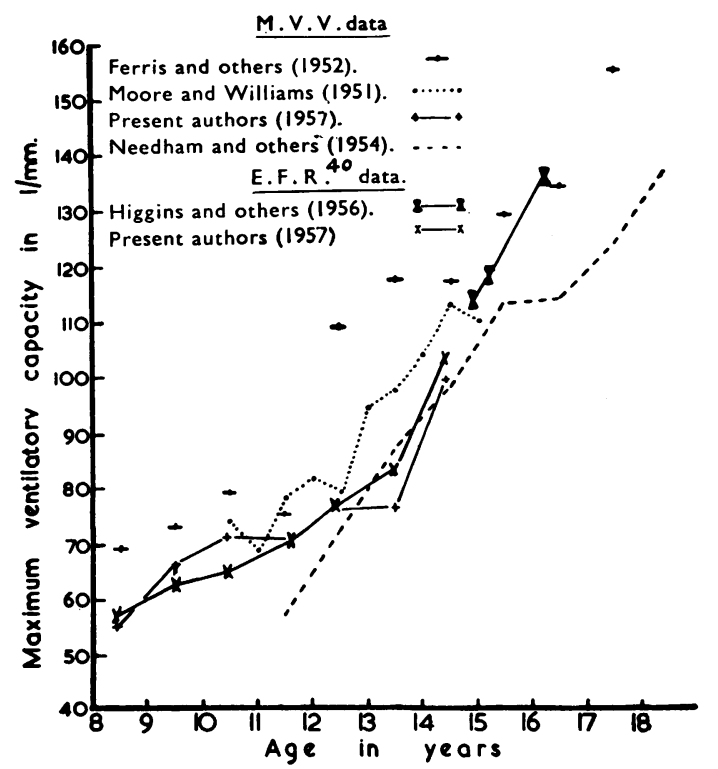

FIG. 7.

Except for our group aged 13 years, our M.V.V. and E.F.R. ${ }^{40}$ curves in Fig. 7 run roughly half way between Moore and Williams' M.V.V. curve and that of Needham et al. Needham et al. used a Douglas bag to obtain their M.V.V. data, and the difficulty of ensuring full cooperation with this technique may be responsible for their lower values. Bernstein et al. (1952) have shown the effect of different rates of breathing on the M.V.V. and they also show the effects of oscillating water columns in various spirometers in enhancing M.V.V. values. Our experiences with spirometer A and spirometer B support their findings. The relatively higher values of Moore and Williams may be partly explained by the size of the children and possibly by the enhancing effect of water oscillation within their spirometer: The same arguments may possibly explain the even higher values obtained by Ferris, Whittenberger and Gallagher (1952). Our own E.F.R. ${ }^{40}$ data and those of Higgins et al. appear compatible: this is perhaps not surprising, because unlike the M.V.V. test the E.F.R. ${ }^{40}$ test is not susceptible to different breathing rates nor is it affected much by an oscillating water column. McDermott and McKerrow (1956) have also shown the E.F.R. ${ }^{40}$ to be largely independent both of the resistance at the mouth-piece orifice and of the patient's cooperation provided a full inspiration is taken.
Prediction Formulae. Table 2 shows that age, height, weight and chest circumference are all correlated with the various spirometric measures. These findings would agree with the suggestion by Whitfield, Waterhouse and Arnott (1950) and that of Ferris et al. (1952) that a number of physical attributes, including body surface area, should be employed for the prediction of normal vital capacity and M.V.V. values. However, we are interested in the prediction of so-called normal values in abnormal children, and the use of such indices as weight and chest circumference would obviously be fallacious in those children emaciated from certain diseases and those with chest deformities. Whereas in adolescents age shows a positive correlation with spirometric measures, there is a negative correlation in adults (Hutchinson, 1846 ; Baldwin, Cournand and Richards, 1948; Gilson, Hugh-Jones, Oldham and Meade, 1955). Thus clearly, formulae for the prediction of normal values in children which incorporate age are not applicable to adults and vice versa. The position in regard to weight is more complicated, since although in general weight is positively correlated with spirometric measures in both children and adults, excessive weight or obesity is associated with a reduction of the normal vital capacity (Hutchinson, 1846) and in all probability with a reduction of other spirometric measures also. It would thus appear that either standing height or sitting height is the most important single index for the prediction of normal spirometric values.

Although some authors use surface area (Moore and Gibson-Williams, 1951; Ferris, et al., 1952), we have followed the practice of others in using height as our main index for the prediction of the different spirometric measures. Hutchinson (1846) in his classic treatise on the vital capacity discussed various groups of normal young adults, and estimated that for every inch increment of height from 5 to $6 \mathrm{ft}$., 8 additional cu. in. air $\left(131 \mathrm{c.cm}\right.$.) at $60^{\circ} \mathrm{F}$. (cf. our prediction formula for vital capacity) are given out by forced expiration. Baldwin et al. (1948) also use height as their main index for the prediction of normal vital capacity values although they use body surface area for the prediction of normal M.V.V. values. Everley Jones (1955) measured the vital capacity of boys and girls and plotted height, weight and surface area against vital capacity. He was able to corroborate the finding of Baldwin et al. that the most smoothly rising curve in each sex was that recording vital capacity against height. It should be emphasized that the various prediction formulae for the E.F.R. ${ }^{40}$, I.F.R. ${ }^{40}$, V.C. and M.V.V. given in this paper are only strictly applicable to boys aged 10-15 years. 
However, for practical purposes they are probably near enough for boys aged 7-18 years, although the values at either end of this age range are on the low side. The prediction formulae are not applicable to children and adolescents outside the 7-18 years range.

The standard deviations of the distributions of normal values (for a given height and age) are quite large: 10.7 litres per minute, for example, for E.F.R. ${ }^{40}$. It is important, therefore, to remember that deviations from the predicted value of 20 to $30 \%$ are not uncommon even in boys in whom no significant abnormality can be demonstrated. A deviation of this magnitude should be regarded as suspicious, but far from conclusive.

Although we have not studied girls, there seems to be good evidence that normal boys and girls of the same height have very similar vital capacities (Everley Jones, 1955) and M.V.V.s (Ferris et al., 1952; Ferris and Smith, 1953). Consequently we employ the same formulae for the prediction of normal values in girls as we use for boys.

Baldwin et al. (1948) measured the vital capacity data on adults, and on comparing their findings with those of Kaltreider et al. (1938) and Robinson (1938), they found that values decreased with age to about the same degree in both sexes. However, in adult life females have a lower vital capacity and a lower maximum ventilatory capacity than men of similar height and surface area (Baldwin et al., 1948). Consequently formulae for the prediction of normal values in adults must allow for this sex factor.

Indices of Maximum Ventilatory Capacity (M.V.C.). Since introduced by Hermannsen in 1933 the M.V.V. test, recorded by means of a spirometer or a Douglas bag, has until recently been generally accepted as the best index of maximum ventilatory capacity. This test is time-consuming to both patient and observer and even if the technical problems already mentioned are eliminated the test is not suitable for routine out-patient work or for the assessment of severely disabled patients. Although we agree with Bernstein and Kazantzis (1954) and Shephard (1955) that the M.V.V. is well correlated with I.F.R. ${ }^{40}$ in normals $(R=0.986)$ we have rejected this I.F.R. ${ }^{40}$ as an index of M.V.C. on two counts. First, in patients with ventilatory insufficiency it will nearly always be found that expiration is the limiting factor to hyperventilation. Second, to obtain satisfactory inspiratory curves (I.V.S.) the patient must always give of his best, whereas satisfactory expiratory curves (E.V.S.) are largely independent of the patient's cooperation, providing a maximal inspiration has been taken first.
For these reasons we employ the E.F.R. ${ }^{40}$ test as our measure of maximum ventilatory capacity. We propose to retain the term E.F.R. ${ }^{40}$ (expiratory flow rate at theoretical breathing rate of 40 breaths per minute), because it describes the test and because the values are expressed in litres per minute which is the correct index for assessing ventilatory reserve.

Although the lungs must be capable of effective diffusion and be supplied with an adequate pulmonary blood flow to function properly under varying conditions and stresses, it has become more apparent during recent years that many respiratory diseases are disabling because they diminish the effective ventilatory capacity of the lungs. This argument applies particularly to such diseases as acute and chronic bronchitis (Westlake, 1955), acute and chronic asthma (Beale, Fowler and Comroe, 1952; Kennedy and Thursby-Pelham, 1956), localized cysts and generalized emphysema (Baldwin, Harden, Green, Cournand and Richards, 1950; Gaensler, 1951) and also patients with generalized lung fibrosis (Gilson et al., 1955).

During our longitudinal study of asthmatic children over the past six years, we have for the above reasons been particularly interested in assessing the maximum ventilatory capacity by means of the E.F.R. ${ }^{40}$ test. When this test is applied to any individual child, it can be seen immediately whether there is any qualitative abnormality of the E.V.S., and by expressing the E.F.R. ${ }^{40}$ as a percentage of the predicted value, an index of the relative normality of the maximum ventilatory capacity is readily obtained, always bearing in mind the considerable range observed even in normal children.

\section{Summary}

One hundred and seventy-five schoolboys were selected at random from a school in the Stoke-onTrent area to provide an unbiased sample of 25 normal boys for each year of life between the ages of 8 and 14 inclusive.

The anthropometric findings of these boys, which included height, sitting height, weight and various chest measurements, are reported.

The spirometric measures of these boys, which included the vital capacity (V.C.), maximum voluntary ventilation (M.V.V.), inspiratory flow rate at a theoretical breathing rate of 40 breaths per minute (I.F.R. ${ }^{40}$ ) and the expiratory flow rate at a theoretical breathing rate of 40 breaths per minute (E.F.R. ${ }^{40}$ ), are also reported.

The intercorrelation of the various anthropometric and spirometric findings are discussed and regression equations for the prediction of normal 
values of the spirometric measures on the basis of standing height and age are given.

It is considered that the maximum ventilatory capacity of children and adolescents is best obtained by means of the E.F.R. ${ }^{40}$ test, and a simple nomogram is given to facilitate the prediction of normal values.

The expiratory vital spirogram which is obtained during the course of the E.F.R. ${ }^{40}$ test is of considerable clinical value in the assessment of individual patients.

We should like to thank Dr. Vera Veitch, Deputy Principal School Medical Officer to the Education Committee, and Mr. G. L. Light, Headmaster of Moorland Road C.P. Junior School, Stoke-on-Trent, for their invaluable help in arranging this investigation. We are indebted to Mr. J. Booth, S.R.N., Mr. T. E. Bromley, S.R.N. and Mr. L. Drury for skilled technical assistance, and also to the Photographic Department, St. Bartholomew's Hospital, London, for the figures.

\section{REFERENCES}

Baldwin, E. de F., Cournand, A. and Richards, D. W. (1948) Medicine, (Baltimore), 27, 243.

-.-, Harden, K. A., Greene, D. G., Cournand, A. and Richards, D. W. (1950), Ibid., 29, 169.
Beale, H. D., Fowler, W. S. and Comroe, J. H. (1952). J. Allergy, 23,1 .

Bernstein, L., d' Silva, J. L. and Mendel, D. (1952). Thorax, 7, 255. - and Kazantzis, G. (1954). Ibid., 9, 326.

Emerson, P. W. and Green, H. (1921). Amer. J. Dis. Child., 22, 202. Ferris, B. G. and Smith, C. W. (1953). Pediatrics, 12, 341.

-, Whittenberger, J. L. and Gallagher, J. R. (1952). Ibid., 9, 659.

Gaensler, E. A. (1951). Amer. Rev. Tuberc., 64, 256.

Gilson, J. C. and Hugh-Jones, P. (1949). Clin. Sci., 7, 185.

G, - Oldham, P. D. and Meade, F. (1955). Spec. Rep. Ser. med. Res. Coun. (Lond.), No. 290.

Hermannsen, J. (1933). Z. ges. exp. Med., 90, 130.

Higgins, I. T. T., Oldham, P. D., Merrick, A. J. and Dunsdon, M. I. (1956). Brit. J. prev soc. Med. 10, 32.

Hutchinson, J. (1846) Med.-chir. Trans., 29, 169.

Jones, H. Everley (1955). Archives of Disease in Childhood, 30, 445.

Kaltreider, N. L., Fray, W. W. and Hyde, H. van Z. (1938). Amer. Rev. Tuberc., 37, 662.

Kennedy, M. C. S.'(1953a). Thorax, 8, 73.

- (1953b). Proc. roy. Soc. Med., 46, 539.

and Thursby-Pelham, D. C. (1956). Brit med. J. 1, 1511.

McDermott, M. L. and McKerrow, C. B. (1956), 20th Int. Physiol. Congress, Brussels Abstracts of Communications, p. 628.

Morse, M., Schlutz, F. W. and Cassels, D. E. (1952). J. clin. Invest., 31,380

Moore, R. E. and Gibson-Williams, M. G. (1951). Gt Ormond Str. J., 1, No. 2, p. 137.

Needham, C. D., Rogan, M. C. and McDonald, I. (1954). Thorax, 9,313

Robinson, S. (1938). Arbeitsphysiologie, 10, 251.

Shephard, R. J. (1955). Thorax, 10, 258.

Stewart, C. A. (1922). Amer. J. Dis. Child., 24, 451.

Westlake, E. K. (1955). Brit. med. J., $2,960$.

Whitfield, A. G. W., Waterhouse, J. A. H. and Arnott, W. M. (1950). Brit. J. soc. Med. 4, 113.

Wilson, M. G. and Edwards, D. J. (1921). Amer. J. Dis. Child., $22,443$.

Wright, G. W. (1946). Occup. Med., 2, 546. 